\title{
LÍNGUA INGLESA: ASPECTOS DE SUA UNIVERSALIDADE
}

\author{
Rainan Marques Santos Andrade \\ Giêdra Ferreira da Cruz.*
}

RESUMO: Este artigo tem como objetivo analisar a conjuntura política, econômica e social que envolve o uso do inglês como língua universal. É fato que a língua inglesa tornou-se a mais falada em todo o mundo. Mesmo em países cujos idiomas diferem do inglês, de certa forma, já existem estímulos sociais e econômicos para que se aprenda o idioma. Procurando compreender tais aspectos, este estudo realizou um levantamento bibliográfico acerca da temática contemplando uma interpretação teórica dos elementos que contribuíram para a proeminência da língua inglesa como fenômeno global. Assim, no intuito de contextualizar, também, o papel desempenhado pelo o inglês na contemporaneidade, bem como as relações de poder existentes nas entrelinhas, respaldamo-nos no aporte teórico do campo da linguística aplicada.

PALAVRAS-CHAVE: Globalização; Língua Inglesa; Língua Universal.

\section{Introdução}

É notório que há uma diversidade de idiomas e dialeto, no entanto, “a globalização declina-se preferencialmente em inglês" (ORTIZ, 2004, p.5). Esse fato está relacionado com aspectos bem objetivos que, no geral, não envolvem os fundamentos fonéticos e gramaticais que a compõe, mas os aspectos políticos, econômicos e sociais que interligam e universalizam as relações dentro de um mundo global.

Dentro dessa perspectiva, o aprendizado de uma nova língua não se limita a obter conhecimento acerca dos aspectos fonéticos e fonológicos que a tecem. Esta é apreendida quando o falante, de certa forma, percebe que obterá vantagens em utilizar e se comunicar naquele determinado idioma levando em consideração a amplitude do seu raio de atuação. "O uso do inglês decorreria assim das vantagens que proporciona aos que dele se utilizam"

\footnotetext{
* Mestrando em Letras: Cultura, Educação e Linguagens pela Universidade Estadual do Sudoeste da Bahia (Uesb).

** Doutora em Língua e Cultura pela Universidade Federal da Bahia (Ufba). Professora Titular da Universidade Estadual do Sudoeste da Bahia (Uesb).
} 
(ORTIZ, 2004, p.7). Nessa direção, há uma grande procura de cursos de idiomas, não só por quem deseja ter um “diferencial no currículo”, mas, também, por aqueles que almejam trilhar carreiras acadêmicas. A maioria das seleções de mestrados e doutorados de grandes instituições do Brasil e exterior exige o domínio do inglês considerado, ao redor do mundo, como língua franca ou universal.

Nesse contexto, o qual, a língua inglesa é de fato a mais falada inclusive entre não nativos (LEFFA, 2001), há uma forte influência no que diz respeito à produção e publicação de livros, artigos, entre outros. A grande maioria das obras de renomados autores das variadas áreas do conhecimento são lançadas no idioma muito em virtude, também, do alcance mercadológico da obra em questão que será muito maior, sendo publicada no "idioma universal", do que, por exemplo, em português.

A língua inglesa ostenta o título de idioma "número um" do sistema capitalista contemporâneo (ORTIZ, 2004). Grandes potências econômicas mundiais falam o inglês. Países como China e Japão, mesmo não o tendo como idioma oficial, sofrem influência dessa língua; sendo que, para se trabalhar nesses grandes centros empresarias, faz-se necessário o seu amplo domínio. Dessa forma, num ritmo acelerado, essas influências chegaram a países emergentes, de modo que, hoje, existem diversas vertentes do idioma levando em consideração os aspectos culturais e sociais de cada país.

No caso do Brasil a procura pela aprendizagem da língua inglesa é cada vez maior. Segundo dados da Catho ${ }^{1}$, mais de 70\% das empresas internacionais procuram profissionais que dominem esse idioma. Outro aspecto relevante está voltado, mais uma vez, às questões econômicas: o salário de uma pessoa com amplo domínio do inglês (níveis avançados ou fluentes), se comparado a outras pessoas com a mesma qualificação profissional, pode ser quase 61\% maior. Segundo a Catho, em cargos de diretoria, a diferença de salário entre alguém que fala inglês fluentemente e um profissional que não tem essa habilidade é de $42 \%$. Para os cargos de gerência, supervisão, a diferença é de $57 \%$ e $43 \%$, 
respectivamente. Os dados sinalizam que quanto mais alto o nível hierárquico, maior se torna o porcentual das pessoas que dominam o inglês. No que diz respeito às funções de níveis júnior/pleno/sênior, ou funções de assistente, auxiliares e operacionais, possuem salários de até $45 \%$ e 18\% maiores, respectivamente, nos aponta o estudo. Dessa forma, as razões pelas quais muitos buscam o aprendizado do inglês estão relacionadas, em sua maioria, a uma melhor perspectiva salarial e de emprego.

É importante ressaltar que a língua inglesa já faz parte do cotidiano dos brasileiros. É comum observarmos termos do idioma em diversas áreas do conhecimento, a exemplo de shopping center, playstation, look, hamburguer, hot dog, download, site, pen drive, light, milk-shake, etc. Estes anglicismos permeiam as relações de maneira tão naturalizada que as pessoas, em geral, não se dão conta de como a língua inglesa está incorporada em seus hábitos mais triviais.

Contudo, para além dos vocábulos, os padrões de consumo norte-americanos têm forte influência sobre as perspectivas de consumo e entretenimento no Brasil. Os Estados Unidos são o referencial em termos de expressividade de consumo em todo o globo e suas características são incorporadas pelos países, sobretudo, em desenvolvimento. No entanto, em geral, as pessoas não percebem que são altamente influenciadas por uma conjuntura política, econômica e social que as condicionam ao estudo da língua. Nesse sentido, aqueles que não buscam o conhecimento da língua inglesa, estariam despreparados para o forte e concorrido mercado de trabalho e acadêmico.

Considerando todas essas questões, este trabalho encontra-se contextualizado na Linguística Aplicada e ancorado, principalmente, em autores tais como, Kumaravadivelu (2006), Leffa (2001), Moita Lopes (2006) Pennycook (1994), tendo em vista que as discussões aqui abordadas não denotam apenas uma questão linguística, mas, sobretudo, as diversas vertentes que se colocam como possibilidades de reflexão. Assim, este estudo visa contribuir para uma melhor compreensão acerca das conjunturas que envolvem a consolidação do inglês como uma língua franca, bem como analisar as entrelinhas contidas no título de 'idioma universal'. O texto está estruturado em duas seções. A primeira está relacionada à comunicação mundial e a relevância do inglês evidenciando os aspectos da 
globalização. A segunda sinaliza a supremacia da língua inglesa trazendo como exemplo a forma com a qual se reflete na academia, isto é, na linguagem científica. E por fim, apresentamos as considerações finais.

A comunicação mundial e a relevância da língua inglesa na globalização

No final do século XX, argumentava-se que estaria no limiar de um novo tempo. Nesse contexto, uma variedade de termos começou a surgir como nomenclatura para esta transição. Muitos desses nomes se referiam positivamente à emergência de um novo tipo de sistema social tais como "sociedade da informação" ou "sociedade de consumo". Contudo, Giddens (2009) nos diz que mais que um estado de coisas precedente, "está chegando a um encerramento 'pós-modernidade', 'pós-modernismo', 'sociedade pós-industrial' e assim por diante" (GIDDENS, 2009, p. 8).

Muitos dos debates que envolvem essas questões estão associados principalmente às transformações institucionais cuja particularidade aponta o deslocamento de um sistema baseado na manufatura de bens materiais para outro ligado à informação. Nessa perspectiva, a língua surge como um fator importante ao passo que começará a nortear tais mudanças favorecendo a propagação numa escala global; isto é, "estamos alcançando um período em que as consequências da modernidade estão se tornando mais radicalizadas e universalizadas" (GIDDENS, 2009, p, 9). Nesse contexto, Giddens (2009) nos afirma que os modos de vida produzidos pela modernidade são completamente distintos de todos os tipos tradicionais de ordem social, sobretudo, em sua extensionalidade e intensionalidade. Do ponto de vista extensional, ressalta o autor, estas serviram para estabelecer diversas maneiras de interconexão social em todo o globo; ao passo que, nos aspectos intensionais, surgiram de modo a alterar algumas características pessoais cotidianas da existência humana.

O ritmo de mudança intensa característico da modernidade é, justamente, uma das descontinuidades que diferencia as instituições sociais modernas das ordens sociais tradicionais (GIDDENS, 2009). Nesse âmbito, o autor considera os aspectos dinâmicos de outras civilizações tradicionais; no entanto a rapidez das mudanças na perspectiva da modernidade 
é extrema. As transformações advindas com a interconexão entre o globo bem como as particularidades das instituições modernas são outras formas de descontinuidades que, de certa forma, diferenciam estas das tradicionais. De acordo com Giddens (2009),

\begin{abstract}
Algumas formas sociais modernas simplesmente não se encontram em períodos históricos precedentes — tais como o sistema político do estado-nação, a dependência por atacado da produção de fontes de energia inanimadas, ou a completa transformação em mercadoria de produtos e trabalho assalariado. Outras têm apenas uma continuidade especiosa com ordens sociais pré-existentes. Um exemplo é a cidade. Os modernos assentamentos urbanos freqüentemente incorporam os locais das cidades tradicionais, e isto faz parecer que meramente expandiram-se a partir delas. $\mathrm{Na}$ verdade, o urbanismo moderno é ordenado segundo princípios completamente diferentes dos que estabeleceram a cidade pré-moderna em relação ao campo em períodos anteriores. (GIDDENS, 2009. p. 12)
\end{abstract}

Dentro dessa perspectiva, torna-se fundamental ressaltarmos a criação da internet. Castells (2000) nos afirma que o seu desenvolvimento, nas três ultimas décadas do século $\mathrm{XX}$, foi resultado da união entre estratégias militares, cooperação científica, e iniciativas de inovação tecnológica. Aqui é importante pontuar que internet foi criada por uma das mais renomadas instituições de pesquisa do mundo: a Agência de Projetos e Pesquisa Avançada (ARPA) do departamento de defesa dos Estados Unidos, sendo que muitos dos empreendimentos da ARPA mudaram os rumos da tecnologia mundial, iniciando a era da comunicação em grande escala.

A ideia inicial com a criação da internet e da informação em grande escala, nos afirma Castells (2000), foi criar um sistema de comunicação invulnerável aos ataques nucleares. Mais tarde, a tecnologia digital também passou a permitir o empacotamento de diversos tipos de mensagem tais como áudio, imagem, entre outros. O autor ressalta a universalidade da linguagem digital e a lógica das redes do sistema de comunicação como bases das condições tecnológicas para uma comunicação global horizontal.

Podemos observar que a internet, sem dúvida, nos apresentou um novo modelo de estabelecimento das relações comerciais juntamente com todas as perspectivas de mercado atual. Nesse sentido, percebemos que a maioria das negociações e relações entre países são 
realizadas na língua inglesa por ser, como nos apontam Friedrich e Matsuda (2010), a língua dominante do comércio internacional.

Nesse contexto, a ascensão da telefonia móvel por volta do ano de 1997, liderada por grandes marcas como a Nokia e Ericsson, ganha destaque nesse processo. Esses avanços, nos afirma Castells (2000), proporcionaram uma maior capacidade de transmissão que somada a tecnologia de comunicação favoreceram a utilização da internet ou de outras tecnologias para transmitir voz e dados; esse fato revolucionou a indústria da telecomunicação. É importante considerar que as descobertas das novas tecnologias da informação se concentraram nos Estados Unidos da América. Sobre este fato, o autor ressalta a relação desta com o atual contexto social dos EUA que em 1970 enfrentava uma forte crise econômica. Nessas circunstâncias, o avanço tecnológico foi motivado e tido como um grande aliado no processo de restruturação do sistema capitalista em escala global.

Assim sendo, de acordo com Friedriche e Matsuda (2010), o inglês também é considerado como a linguagem da tecnologia, pois, para elas, esse fato contribuiu bastante para o seu estabelecimento e consolidação em todo o mundo. Contudo, Kumaravadivelu (2006) nos diz que esse título de língua da tecnologia se deu muito em virtude de ser o idioma o qual se constituiu o conceito de comunicação no contexto atual de globalização. Como vemos a seguir:

Em um desenvolvimento sem precedentes na história humana, a internet tornou-se uma fonte singular que imediatamente conecta milhões de indivíduos com outros, com associações particulares e com instituições educacionais e agências governamentais, tornando as interações a distância e em tempo real possíveis. E a língua da globalização - claro, o inglês - está no centro da [era] contemporânea. (KUMARAVADIVELU, 2006, p. 131)

Para Giddens (2009, p.55), o fenômeno da globalização "consiste numa surpreendente intensificação das relações sociais mundiais através das quais acontecimentos locais podem ser regulados a milhares de quilômetros de distância". Essa intensificação acontece mediante ao estabelecimento de um mesmo código linguístico. O autor também acredita que o desenvolvimento das relações sociais globalizadas favoreceu a diminuição de alguns 
aspectos do sentimento nacionalista ligados aos estados-nação. No entanto, ao mesmo tempo, esse pode estar relacionado à intensificação de sentimentos nacionalistas mais localizados. Dessa forma, segundo Giddens (2009), ao mesmo tempo em que as relações sociais se tornaram esticadas; como parte do mesmo processo, percebe-se o fortalecimento de pressões para certa autonomia local que reforcem a identidade cultural e regional. No entanto, também existem autores, Milton Santos (2000), por exemplo, que consideram esse fato por um viés mais crítico; atribuindo à globalização como um movimento perverso e excludente.

Segundo Santos (2000), a globalização surge como uma fábrica de perversidade ao passo em que o desemprego torna-se cada vez mais crescente; fato que contribui consideravelmente para o aumento da pobreza e a queda da qualidade de vida por parte das classes médias. A incoerência é outro aspecto negativo da globalização, ainda para Santos (2000), a permanência da mortalidade infantil mesmo em meio aos grandes avanços tecnológicos e progressos médicos, é um forte exemplo dessa incoerência. Dessa forma, a perversidade, aqui tida como sistêmica, que está nas bases dessa evolução, é considerada pelo autor como negativa na medida em que estimula comportamentos competitivos. Todas essas difíceis realidades, de certa forma, estão relacionadas direta ou indiretamente ao processo de globalização. Na visão de Santos, poderia se pensar na construção de um mundo diferente considerando uma globalização mais humana. O autor pontua algumas bases materiais da atualidade a exemplo da unicidade da técnica, a convergência dos momentos e o conhecimento do planeta. Esses, ainda de acordo com o autor, seriam as bases técnicas cujo capital se apoia para a construção de uma globalização perversa e excludente.

A globalização surge como o ápice do processo de internacionalização do mundo capitalista (SANTOS, 2000). No entanto, para compreendê-la, tornam-se relevantes pelo menos dois aspectos: o estado das técnicas e o estado da política. Os avanços das técnicas surgiram no fim do século XX mediante o avanço da ciência. Nessa direção, o autor pontua que

Há uma relação de causa e efeito entre o progresso técnico atual e as demais condições de implantação do atual período histórico. É a partir da unicidade das técnicas, da qual o computador é uma peça 
central, que surge a possibilidade de existir uma finança universal, principal responsável pela imposição a todo o globo de uma maisvalia mundial. (SANTOS, 2000. p. 13)

Segundo Santos (2000), aos atores mais poderosos desta nova globalização, reservam-se os melhores pedaços do território global ao passo de deixarem os restos para os outros. Ele ainda afirma que a grande perversidade na produção da globalização atual não está somente na polarização da riqueza e da pobreza, na segmentação dos mercados, na destruição da natureza, mas na construção de um espaço simbólico de dominação muito em virtude da tirania do dinheiro e da informação.

Assim, ao considerar a emergência dessa dupla tirania: a do dinheiro e da informação, percebemos que ambas estão completamente relacionadas, sendo essas duas tiranias a base do sistema ideológico que, de certa forma, legitima o comportamento característico desta época. Para o autor, elas buscam conformar um novo ethos das relações sociais e interpessoais, isto é, o processo de globalização perverso e excludente que influencia diretamente no comportamento e no caráter do "novo cidadão". O geógrafo acredita que, toda dinâmica de competitividade impulsionada pela produção e consumo, surgem como novos totalitarismos que são facilmente aceitos devido à confusão moral e espiritual instalada nesse processo.

Nesse contexto "totalitário", tudo que se transmite à maioria das pessoas ao redor do mundo é, na visão do autor, uma mídia informativa totalmente manipulada em virtude de objetivos específicos. Aqui muitos desses conteúdos invadem as empresas, o lar das famílias, como algo hegemônico e ideológico. Santos (2000), ainda ressalta a retórica como uma ferramenta de encantamento do mundo cujos, objetivos estão relacionados à instrução e também ao convencimento da sociedade a interesses bem direcionados. Para o autor,

Estamos diante de um novo "encantamento do mundo", no qual do discurso e a retórica são o princípio e o fim. Esse imperativo e essa onipresença da informação são insidiosos, já que a informação atual tem dois rostos, um pelo qual ela busca instruir, e um outro, pelo qual ela busca convencer. Este é o trabalho da publicidade. Se a informação tem, hoje, essas duas caras, a cara do convencer se torna muito mais presente, na medida em que a publicidade se transformou em algo que antecipa a produção. Brigando pela sobrevivência e hegemonia, em função da competitividade, as empresas não 
podem existir sem publicidade, que se tornou o nervo do comércio (SANTOS, 2000. p. 20).

Nesse panorama, as mídias nacionais também são profundamente influenciadas pelo processo de globalização. Santos (2000) não enxerga esta realidade como algo benéfico, muito pelo contrário, aponta a falsificação dos eventos, das notícias, como aspectos característicos desse processo. Assim, as informações são transmitidas mediante interpretações diversas do fato propriamente acontecido; aqui muitas dessas interpretações são carregadas de valores, visões, preconceitos e interesses particulares dos meios de comunicação. Dessa forma, é justamente por essa razão, que Santos nos afirma que a globalização também é o mundo das fábulas, uma vez que é a perspectiva do mundo como querem nos fazer vê-lo.

Outra fábula apontada pelo geógrafo está relacionada ao espaço e tempo, isto é, os prodígios que a velocidade trouxe ao mundo global. Assim, Castells (2000) corrobora com as ideias de Santos (2000) ao afirmar que essas se encontram ao alcance de um número limitado de pessoas de modo que muitas não utilizam "o mesmo relógio"; o que interfere diretamente na economia e na capacidade de consumo dos indivíduos. O processo de globalização, bem como a perspectiva de espaço-tempo fizeram com que o globo se norteasse pelo viés do mercado global. Dessa forma, coisas, relações sociais, dinheiro, gosto, entretenimento, foram influenciados pelo processo. Por isso, de acordo com o referido autor, torna-se nítida a influência da globalização sobre os continentes bem como nas línguas, raças e religiões.

Entretanto, se não fosse a existência das fábulas, este mundo não existiria tal como é, nos afirma Santos (2000). São justamente essas fábulas que caracterizam a violência simbólica do dinheiro e da informação. Dessa forma, ele nos afirma que tal movimento acarretou sérias mudanças na economia mundial e nas culturas globais que, em sua maioria, "privilegia a abertura de mercados nacionais, a flexibilização de políticas protecionistas, a intercomunicação em tempo real e a suposta prosperidade das diversas nações do planeta" (SANTOS, 2000, p. 18). Autores como, Steger (2003), por exemplo, possuem uma visão mais branda acerca dessas questões. Este a compreende como "uma série multidimensional 
de processos sociais que criam, multiplicam, alargam e intensificam interdependências e trocas sociais no nível mundial" (STEGER, 2003, p. 13).

Por sua vez, Boaventura de Souza Santos (2002), concebe a globalização como um fenômeno que, de maneira extraordinária, transformou as relações transfronteiriças. Assim, a amplitude e profundidade destas interações transnacionais fizeram com que estas conhecessem uma intensificação dramática desde a globalização dos sistemas de produção e das transferências financeiras, à disseminação, a uma escala mundial, de informação e imagens através dos meios de comunicação social ou deslocamento em massa de pessoas, sejam como turistas ou como trabalhadores, migrantes, refugiados. Aqui, o autor, não reduz o fenômeno da globalização somente a dimensões econômicas; mas, também, considera e ressalta suas dimensões sociais, políticas e culturais.

Os aspectos culturais também assumiram um papel importante no processo de globalização. Segundo Santos (2009), os meios de comunicação eletrônicos, especialmente a televisão, têm fomentado grande parte dos debates. Isso porque os valores, os artefatos culturais, os universos simbólicos que se globalizam são ocidentais e em sua maioria norteamericanos; tais como o cinema, a publicidade, a televisão, internet, entre outros. O autor também nos afirma que a globalização surge como um vasto e intenso campo de conflitos entre grupos sociais, Estados e interesses hegemônicos, por um lado; e grupos sociais, Estados e interesses subalternos, por outro; ao passo que mesmo no interior do campo hegemônico existem divisões mais ou menos significativas. Contudo, por sobre todas as divisões internas, o campo hegemônico ainda atual na base de um consenso entre os seus mais influentes membros. Sendo esse consenso o fator que não só confere a globalização suas características dominantes, como também as legitima como únicas possíveis ou adequadas ao fenômeno.

No que diz respeito às relações sócio-políticas, tem-se defendido que, embora o sistema mundial moderno tenha sido sempre estruturado por um sistema de classes, percebemos que uma classe capitalista transnacional emerge tendo o globo como campo de reprodução social. Assim, as empresas multinacionais são a principal forma institucional dessa classe transnacional. A amplitude das transformações que essas empresas provocam 
na economia mundial está diretamente relacionada à sua produção, que ultrapassa mais de um terço do produto industrial mundial. (SANTOS, 2002).

Nessas circunstâncias, é nítido que o inglês assume um papel fundamental no fenômeno de globalização. Leffa (2001) explica que a língua inglesa é comprovadamente o idioma oficial dessas trocas sociais e das interações intra e intercontinentais em tempo real. Segundo o autor,

Há uma série de fatos que contribuem para isso, entre os quais podemos destacar os seguintes: (1) o inglês é falado por mais de um bilhão e meio de pessoas; (2) o inglês é a língua usada em mais de $70 \%$ das publicações científicas; (3) o inglês é a língua das organizações internacionais. A razão mais forte, no entanto, é o fato que o inglês não tem fronteiras geográficas. $O$ inglês, por outro lado, é não só declaradamente a língua oficial de 62 países, mas é também a língua estrangeira mais falada no mundo: para cada falante nativo há dois faltantes não-nativos que a usam para comunicação. (LEFFA, 2001. p.364)

Nessa direção, é valido pensar não só no grande número de países que possuem o inglês como língua oficial, mas também a sua propagação enquanto língua estrangeira mais falada entre não nativos. Desse modo, "O inglês é provavelmente a única língua estrangeira que possui mais falantes não nativos do que nativos" (LEFFA, 2001 p. 364). Nesse sentido, a questão passa a ser não somente econômica e política, como nos remete o termo "língua franca", mas também cultural e social.

\section{A representatividade da língua inglesa e os seus reflexos na ciência}

É importante a compreensão da dimensão e surgimento do termo "língua franca" que se encontra, como foi visto, ligado à economia. Por medidas socioeconômicas, alguns países têm favorecido com regimes administrativos especiais a algumas regiões de seus territórios estabelecendo, dessa maneira, o que se pode chamar de "zona franca". O intuito dessa iniciativa é atrair investidores de modo a gerar empregos e favorecer economicamente a região. No Brasil adotou-se essa disposição no ano de 1968, em Manaus, quando em uma dessas zonas concentrou-se diversas indústrias de montagem de eletrônicos o que 
favoreceu economicamente uma grande parcela da população. Dessa forma, o termo "franca" implica em algumas considerações como: "entrada franca", "sinal verde", "acesso irrestrito", "ausência de limites", e tantas outras. Assim, o termo "língua franca"2não se difere do campo de tais considerações ao passo que exprime a ideia de uma língua que sirva para povos de idiomas diversos no objetivo de facilitar e viabilizar a comunicação, sobretudo, no campo das ciências.

Contudo, é importante ressaltar que nem sempre o inglês ostentou esse status científico. Segundo Ortiz (2004) é recente e deriva da evolução cultural do ocidente, uma vez que outros idiomas também já ocuparam o status de "língua franca". O latim, por exemplo, já ocupou essa posição; o francês em virtude do iluminismo setecentista também sustentou este título. No entanto, logo após a I Guerra Mundial, o inglês passou a conquistar espaço se consolidando no cenário mundial como uma hegemonia linguística a exemplo dos dias atuais. Nesse contexto, o autor ressalta que um aspecto importante relacionado aos embates contidos no processo de aceitação da língua inglesa como franca dentro do campo das ciências sociais se deve à dificuldade de traduzir seu variado repertório expressivo diferente das ciências naturais. Assim, tal dificuldade está ligada, sobretudo, a uma questão de natureza do saber construído.

Todo o sucesso e rapidez do estabelecimento da língua inglesa como "primeira" do mundo e, consequentemente, do campo científico também está relacionado a vários outros aspectos. Podemos citar alguns como sendo determinantes: o sucesso das sociedades anglófonas na disputa pelas riquezas do mundo; ao êxito idiomático como resultado dessas conquistas, colonizações e imposições comerciais do império Britânico ao longo de dois séculos. Alguns outros fatores também foram preponderantes na aceleração desse processo tais como a liderança mundial representada pelo poder militar e tecnológico dos Estados Unidos da América e, claro, a expansão da tecnologia.

${ }^{2}$ Em consonância com Jenkins (2006) inglês como língua franca é uma língua de contato entreculturas que não compartilham a mesma língua materna. Para a autora o inglês serve como língua franca entre os falantes não nativos de inglês 
De acordo com Leffa (2001), cerca de 7\% da população possuem o inglês como língua materna. No entanto, outra parcela de pouco mais de $22 \%$ a têm como um segundo idioma. Nos Estados Unidos, diferente do que muitos pensam, o inglês foi estabelecido como língua oficial há pouco tempo; esta oficialização surgiu como ferramenta de amenização de pressões demográficas que estavam flexíveis a inclusão de outros idiomas como, por exemplo, o espanhol. Dessa maneira, segundo a 'Truchot-1990', cerca de 70\% da população mundial (quatro bilhões) vivem na ignorância dessa língua. Contudo, advogamos que a hegemonia do inglês não se avalia quantitativamente; isto é, o fato de uma pessoa conhecer ou não o idioma não pode ser considerado como indício de erudição ou intelectualidade.

Nesse âmbito, o imperialismo científico ganhou força entre os países tidos como desenvolvidos sobre aqueles considerados emergentes. Forattini (1997), pontua algumas características desse fenômeno como, por exemplo: o primeiro mundo (países do ocidente) é considerado como os portadores do ‘saber’ e por essa razão tem a obrigação somente de ensinar favorecendo a "exogenia", isto é, uma supervalorização da formação "além fronteiras" da população destes países subdesenvolvidos. Outro aspecto característico desse processo está relacionado ao fato de os pesquisadores considerarem os países de terceiro mundo somente como fonte de dados (raw material).

Entretanto, sabemos que grande parte da literatura produzida e publicada relacionada à dispersão da língua inglesa pelo mundo é recente. Toda essa bibliografia se desenvolveu, sobretudo, nas décadas de 70 e 80 quando se publicou uma série de livros a respeito desse fenômeno do desenvolvimento do idioma em escala internacional. Contudo, muitas dessas bibliografias apresentam o inglês moldado em padrões consagrados como o britânico e o norte-americano; tal fato fez com que diversos autores, tais como Rajagopalan (2005) e Siqueira (2015), questionassem a padronização do idioma, ressaltando suas variações nas diversas culturas.

De acordo com Ortiz (2004), há entre os países de língua inglesa, uma disputa em torno da existência ou não de um único padrão (ou no máximo dois) capaz de ordenar a hierarquia das falas. Esse fenômeno é percebido desde a formação do Estado-nação do 
qual o monopólio da língua foi um dos traços definitivos no processo de integração nacional. No entanto, é importante pontuar que as tensões não ficaram somente no passado como também é algo extremamente recorrente diante do surgimento e propagação de diversos idiomas no contexto de uma mesma área geográfica. O movimento EnglishOnly, nos Estados Unidos, por exemplo, representa essas tensões numa perspectiva mais atual ao passo que defende o monolinguismo no intuito de desqualificar e limitar a demanda dos imigrantes que defendem uma educação bilíngue.

Nesse contexto, Ortiz (2004) ainda ressalta que o inglês é a língua dos meios de comunicação, da racionalidade, a razão primeira e não uma expressão da supremacia norteamericana. Sendo assim, a prática do inglês nos mais variados meios implica no fortalecimento do padrão da língua no mercado de bens linguísticos. A autoridade do inglês é reforçada e legitimada quando as pessoas o empregam em suas tarefas cotidianas. Um exemplo bastante claro pode ser percebido na vertente musical, ao passo que estas são extremamente ouvidas sem haver, na maioria das vezes, a compreensão. Dessa forma, a legitimidade do inglês é tamanha que prescinde do entendimento dos que o desconhecem. Por outro lado, se tratando da população cientifica mundial, atualmente, como já foi mencionado anteriormente, percebe-se uma tendência em aceitar o inglês como "língua franca da ciência". Assim, essa aceitação seria um meio de se abolir as barreiras da comunicação nesse campo numa perspectiva global de conhecimento; isto é, legitimando uma língua como "oficial da ciência" seria um meio eficaz de se obter visibilidade dos resultados alcançados favorecendo certo "Ibope científico".

Outra questão importante a ser considerada está relacionado ao grande crescimento dos artigos publicados em inglês em diversas áreas cientificas. Em matemática, por exemplo, o Bulletin signalétiquẻaponta que entre 1940 e 1980 houve um crescimento no número

${ }^{3}$ Bulletin signalétique foi iniciado por Julien Cain, administrador da Biblioteca Nacional (BN) e diretor das Bibliotecas da França, o BulletindesBibliothèques de France foi criado em 1956. A revista é o resultado da fusão de duas publicações profissionais: o Bulletin de documentation bibliographique (então publicado desde 1934) e o Boletim Informativo da Direction des Bibliothèques de France (então publicado desde 1952). Fonte: https://bbf.ens- 
de textos produzidos em inglês de 49,5\% para $71 \%$; enquanto o francês caiu de $31,2 \%$ para 6,1\%; o alemão de $13,2 \%$ apara apenas $1,6 \%$.

Nas revistas norte-americanas estes números ainda são mais alarmantes. Na Physics Abstracts ${ }^{4}$ indica que entre as décadas de 50 e 80 as publicações em inglês aumentaram de $70,3 \%$ para 80,6\%; tornando-se a produção em outras línguas quase que insignificantes. Dentro das áreas de conhecimento, entre os anos de 1965 e 1988, as publicações em inglês na área de biologia giravam em torno de $75 \%$; em engenharia passaram de $82 \%$ para $86 \%$; em medicina houve o aumento de $51 \%$ para $75 \%$;.em matemática o número chega aos $82 \%$. Esse aumento, com o passar dos anos, acentua-se em todas as áreas do conhecimento. Há também revistas inteiramente em inglês ou publicações significativas no idioma em revistas nacionais. No Brazilian Journal of Genetic ${ }^{5} 100 \%$ dos textos são em língua inglesa; A Conputationand Applied Mathematics ${ }^{6}$, também no Brasil, 100\% dos textos são em inglês. Em todos os casos se reforça e condiciona o inglês como "língua franca da ciência".

Como pode ser visto, a representatividade da língua inglesa tem seus reflexos na ciência no sentido de influenciar nas publicações de estudos das diversas áreas do conhecimento. Nessa direção, Phillipson (1992) já enfatizava que a dominação da língua inglesa está relacionada, entre outros fatores, ao utilitarismo anglocêntrico, isto é, as possibilidades e o alcance que o idioma tem a oferecer em detrimento dos outros.

\section{CONSIDERAÇÕES FINAIS}

O presente trabalho foi um exercício de compreensão do contexto que permitiu que a língua inglesa alcançasse status global. É notório que nem sempre foi dessa maneira,

${ }^{4}$ AIP Publishing é uma subsidiária integral sem fins lucrativos do American Institute of Physics (AIP)Fonte: https://physicstoday.scitation.org/journal/pto

${ }^{5}$ Geneticsand Molecular Biology (anteriormente denominada Revista Brasileira de Genética / Revista Brasileira de Genética - ISSN 0100-8455) é publicada pela Sociedade Brasileira de Genética. Fonte: https://www.gmb.org.br/

${ }^{6}$ Computational \& Applied Mathematics começou a ser publicado em 1981. Tido como a principal publicação científica da Sociedade Brasileira de Matemática Computacional e Aplicada (SBMAC), o objetivo do periódico é a publicação de pesquisas originais em Matemática Aplicada e Computacional, com interfaces em diversas áreas do conhecimento. Fonte: https://www.springer.com/journal/40314 
mas que em muitos períodos da história outros idiomas se estabeleceram como língua franca e este fato esteve diretamente ligado a questões econômicas. Com o advento da globalização, identificamos a grande contribuição dos Estados Unidos no que diz respeito ao aprimoramento da revolução tecnológica que, de certa forma, é um dos traços desse processo. Assim, vimos alguns pontos que enaltecem o processo de globalização como algo benéfico, mas, simultaneamente, como um movimento excludente e perverso.

Entretanto, é justamente neste contexto iniciado com a colonização, da importância do Império Britânico no século XIX, pela predominância econômica dos Estados Unidos a partir da Segunda Guerra Mundial, momento que se estende até o final do século XX e perpassando a história, que a língua inglesa ganhou tamanha ascensão social e cultural. O inglês surge como um meio do falante adentrar-se em outros campos, acompanhar as intensas transformações socioculturais favorecendo a interação desse indivíduo numa escala global.

Assim sendo, entendemos que uma língua não se tornou global por causa de suas propriedades estruturais, pela extensão do vocabulário, pela bagagem literal e muito menos por ter sido associada a uma grande cultura ou religião. A razão maior pela qual uma língua se torna global está relacionada, no geral, ao poder político, econômico e militar de um povo. Notamos a maneira com que se estabeleceu como a "língua do mercado", "da ciência", "da tecnologia" e do "entretenimento". Dessa forma, o fato de ser um estudante ou falante do idioma está carregado de simbologias em suas entrelinhas que superam as questões fonéticas e fonológicas acerca do seu aprendizado.

Percebemos que, na maioria das vezes, esse fenômeno está ligado a questões de ganhos econômicos, bem como um meio de ascensão social e cultural do falante, uma vez que a língua inglesa surge em um contexto de língua multiterritorializada, de modo a fomentar a comunicação entre as pessoas no contexto global em que estão inseridas. Sendo que esse idioma segue o ritmo das novas transformações, bem como os das crescentes demandas advindas do fenômeno da globalização. Nas palavras de Ortiz (2006, p.14), a língua inglesa "ganha existência própria apta a ser camaleonicamente apropriada, re-significada, re-entoada por falantes de diferentes línguas maternas”. 
De acordo com Cruz (2016, p. 322), “teóricos como Phillipson (1992), Pennycook (1994) e Canagarajah $(1999,2005)$ fazem reflexões importantes sobre a natureza sóciohistórica da expansão da língua inglesa pelo mundo". Para a autora,

O trabalho de Phillipson (1992), por exemplo, denuncia a expansão do inglês como forma de um "imperialismo linguístico", representando uma maneira de dominação, pelos países onde esse idioma é a língua materna da comunidade. Nessa visão, o avanço do inglês causaria um enfraquecimento nas línguas locais. Assim, em um tom de denúncia, ele afirma que esse avanço é meticulosamente financiado por falantes do círculo interno para impor valores socioculturais e linguísticos, que são transmitidos por meio desse idioma. Tal visão é apoiada por Pennycook (1994) que enfatiza que o ensino de línguas não deve estar sujeito às influências políticas e culturais desses países do círculo interno e que, em razão do caráter internacional da língua inglesa, ela não pode ser considerada inocente. (CRUZ, 2016. p. 322)

Pennycook (1994) ao nos alertar sobre o avanço do inglês pelo mundo, afirma que existe uma falsa neutralidade de discursos, aparentemente inocentes, transmitidos como uma língua internacional para a comunicação no planeta terra. Nessa direção, corroboramos com o pensamento de Cruz (2016) quando advoga que precisamos produzir um contradiscurso no sentido de proporcionar ao aprendiz o fortalecimento da sua identidade cultural como estudante da língua inglesa no Brasil, a fim de ter a sua cultura ampliada pelo ganho cultural e linguístico, bem como pelo fortalecimento da sua identidade.

\title{
ENGLISH LANGUAGE: ASPECTS OF ITS UNIVERSALITY
}

\begin{abstract}
This article aims to analyze the political, economic and social situation that involves the use of English as a universal language. It is a fact that the English language has become the most widely spoken in the world. Even in countries whose languages differ from English, somehow, there are social and economic incentives to learn the language. Seeking to understand such aspects, this research carried out a bibliographical survey about the theme, contemplating a theoretical interpretation of the elements that contributed to the prominence of the English language as a global phenomenon. Thus, in order to contextualize the role played by English language in contemporary times, as well as the power relations between the lines, this paper was supported by the theoretical contribution of the field of Applied Linguistics.
\end{abstract}

KEYWORDS: Globalization; English language; Universal language. 


\section{REFERÊNCIAS}

CANAGARAJAH, A. S. Resisting linguistic imperialism in English teaching. Oxford: Oxford University Press, 1999.

CANAGARAJAH, A. S. From Babel to Pentecost: postmodern glottoscapes and the globalization of English. In: Faapi Conference, 30th, Argentina, Sep. 2005. Towards the knowledge society: making EFL education relevant. Argentina: British Council, 2005. p. 2233.

CASTELLS, M. A Sociedade em Rede. São Paulo: Paz e Terra, 2000.

CRUZ, G. F. Inglês como língua global: reflexões sobre o ensino/aprendizagem. Folio (Online): revista de letras, v. 8, p. 315-331, 2016.

FORATTINI, O. P. A língua Franca da Ciência. Rev. Saúde Pública, 31 (1): 3-8, 1997. FRIEDRICH, P.; MATSUDA, A. When five words are not enough: a conceptual and terminological discussion of English as a Lingua Franca. International Multilingual Research Journal, Vol. 4, No. 1, 2010, p. 20-30.

GIDDENS, A. As Consequências da Modernidade; tradução de Raul Fiker. SãoPaulo: Editora UNESP, 2009.

JENKINS, J. Current perspectives on teaching World English and English as a lingua franca. TESOL Quarterly, v. 40, n. 1, 157-181. Março, 2006.

KUMARAVADIVELU, B. A Linguística Aplicada na Era da Globalização. In: MOITA LOPES, L. P. (Org.). Por uma linguística aplicada INdisciplinar. $2^{a}$ ed. São Paulo: Parábola Editorial, 2006 p. 129-148.

LEFFA, V. J. Aspectos políticos da formação do professor de línguas estrangeiras. In: LEFFA, V. J. (Org.). O professor de línguas estrangeiras: construindo a profissão. Pelotas (RS): Educat, 2001, p. 333-355.

MOITA LOPES, L. P. (Org.). Por uma linguística aplicada INdisciplinar. $2^{\mathrm{a}}$ ed. São Paulo: Parábola Editorial, 2006.

ORTIZ, R. Mundialização: saberes e crenças. São Paulo: Brasiliense, 2006.

ORTIZ, R. O inglês e as ciências sociais e o inglês. Revista brasileira de ciências. São Paulo, v. 19, 2004.

PENNYCOOK, A. The cultural politics of English as an international language. London: Longman, 1994.

PHILLIPSON, R. Linguistic Imperialism. Oxford University Press, 1992.

RAJAGOPALAN, K. A geopolítica da língua inglesa e seus reflexos no Brasil: por uma política prudente e propositiva. In: LACOSTE, Y (Org.). A geopolítica do inglês. São Paulo: Parábola Editorial, 2005.

SANTOS, B. S. (Org.). A globalização e as ciências sociais. São Paulo: Cortez, 2002.

SANTOS, B. S, Meneses, M. P. Epistemologias do Sul. Coimbra Almeidina, 2009.

SANTOS, M. Por uma outra globalização: do pensamento único à consciência universal. Rio de Janeiro: Editora Record, 2000.

SIQUEIRA, S. O desenvolvimento da consciência cultural crítica como forma 
de combate à suposta alienação do professor brasileiro se inglês. IN: Revista Inventário. 4. Ed., jul/2005. Disponível em: $\leq$ http://www.inventario.ufba.br/04/04ssiqueira.htm>. Acesso em: 02 Nov. 2020.

STEGER. M. Globalization: A very short introduction. Oxford University Press Inc. New York. 2003.

Recebido em: 12/11/2020.

Aprovado em: 17/01/2021. 